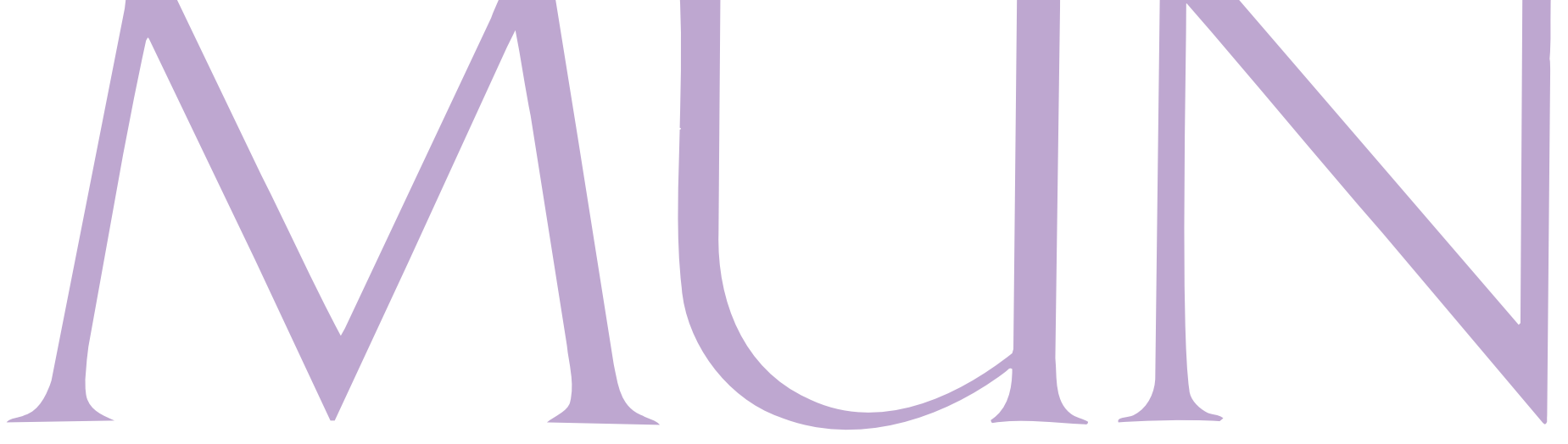

\section{INSTITUTO ANTÁRTICO CHILENO \\ Criado em 1963, o Instituto Antártico Chileno (Inach) é um órgão técnico ligado ao Ministério das Relações Exteriores do Chile responsável pela criação, coordenação e execução de todas as atividades realizadas no Território Antártico Chileno. Desde 2003 a sede do Inach está na cidade de Punta Arenas, que serve como uma porta de entrada do Chile para o Continente Branco. O Inach também é responsável pela realização de atividades de divulgação e avaliação do conhecimento sobre a Antártida na comunidade nacional, e a Feira Antártica Escolar é uma delas.}

experiência. "A Feira Antártica Escolar é uma oportunidade para a formação de uma cultura científica no Chile porque as experiências dos estudantes e professores têm efeito multiplicador. Com isso é possível criar espaços para o diálogo entre cientistas e cidadãos", acredita.

Patrícia Mariuzzo

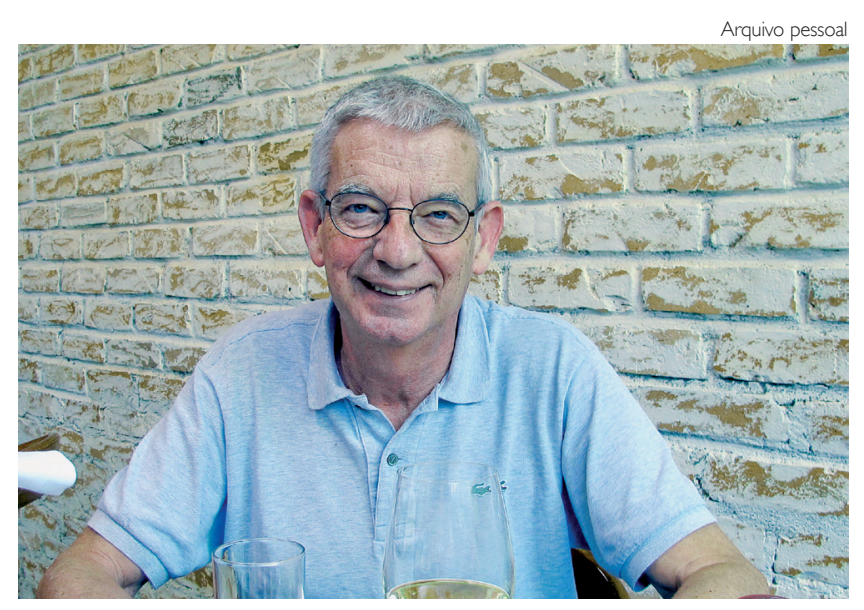

"Só os humanos têm uma sensibilidade tão aguda para o tempo que os tornam capazes de se deslocar em pensamento no tempo - até pensar em sua própria morte", afirma Rémy Lestienne

Entrevista Rémy Lestienne

\title{
A possibilidade da emergência para entender o surgimento de novas propriedades
}

Como funcionam a consciência e o livre arbítrio? E a vida na Terra, como surgiu? São questóes como essas, ainda não respondidas pela ciência, que o conceito de emergência se propóe a abordar. "A ideia da emergência pretende oferecer um caminho para entender como esses 'milagres' são possíveis, sem recorrer a causas transcendentais”, propõe o físico e neurocientista francês Rémy Lestienne, diretor de pesquisa no Centro Nacional de Pesquisa Científica da França (CNRS). Ele é autor de vários artigos e livros sobre o tema. O mais recente, Dialogues sur l'émergence, lançado em 2012 na França pela editora Le Pommier, ainda não tem versão em português. Nesta entrevista Lestienne explica que a ideia de emergência se contrapóe ao reducionismo científico, que busca apreender os fenômenos por meio do estudo dos elementos que compóem um sistema. Diferentemente, a proposta é compreender a organização espontânea de grandes sistemas e de que maneira eles adquirem propriedades novas, não antecipadas pelo estudo dos elementos que os integram. E descreve um exemplo de emergência na revoada de um bando de estorninhos: "no início eles voam em desordem, mas logo a colônia se organiza espontaneamente para tomar uma direção". 


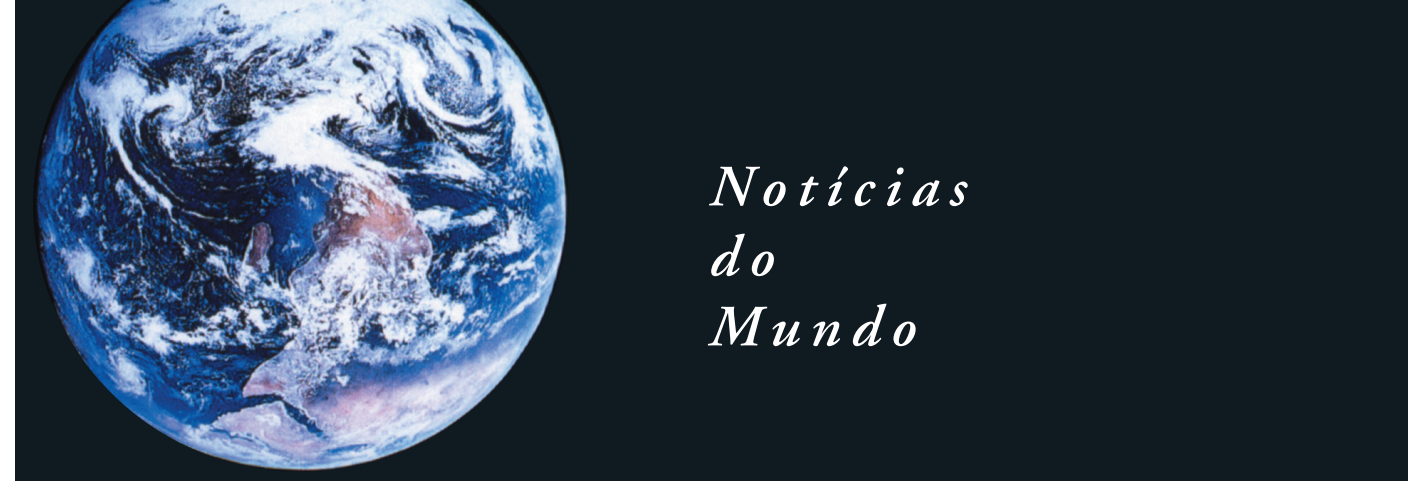

Em seu último livro o senhor diz que, tradicionalmente, a ciência procura desvendar os fenômenos buscando compreender o mais simples, a partícula elementar. Mas há exemplos na natureza de que o todo não se reduz às partes que o integram, mas é composto pelos processos e dinâmicas que o constituem. Isso quer dizer que a ciência, tal como o cidadão comum a conhece, está errada?

Não diria que a ciência, tal como ela é ensinada nas escolas e praticada pelos pesquisadores, esteja errada, mas sim que ela parece incompleta. O reducionismo científico - o método de buscar explicaçóes para os fenômenos observados no estudo dos elementos que compóem o sistema - é muito poderoso e, sem dúvida, permitiu desenvolver a nossa civilização tecnológica. Mas ele não esclarece como a vida emergiu há mais de 3 bilhôes anos na Terra, nem como a consciência - isto é, a representação de si mesmo e dos outros na cena do mundo e a faculdade de interferir no seu desenrolar -, apareceu nos sistemas nervosos dos animais superiores. A ideia da emergência nas ciências pretende oferecer um caminho para entender como esses "milagres" são possíveis, sem recorrer a causas transcendentais. Mais que uma descoberta, ele aponta fatos que são bem conhecidos, mas geralmente negligenciados pela ciência reducionista. $\mathrm{O}$ fato, por exemplo, de que muitas propriedades do mundo onde vivemos não podem ser atribuídas a unidades elementares, como os átomos ou as partículas elementares, mas somente a conjuntos enormes de tais elementos. A forma estável das moléculas e de cristais, de modo geral, não pode ser definida por apenas uma molécula, mas por edifícios grandes e complexos. A ideia tão poderosa na física contemporânea de "quebra espontânea de simetria” para explicar a aparição de propriedades novas, tal como o ferromagnetismo, não está distante da ideia de emergência.

O conceito de emergência influi na vida cotidiana ou implica numa mudança da maneira como percebemos e nos relacionamos com o mundo? A emergência é, em primeiro lugar, outra visão do mundo, uma filosofia que se opóe à filosofia do reducionismo. Aristóteles já pensava assim, quando escreveu que "a totalidade é mais do que a soma das suas partes". Os emergentistas acreditam que, para explicar o que ainda resta a descobrir no mundo, é preciso compreender melhor como a organização espontânea de grandes sistemas é possível, e como eles podem adquirir, às vezes, propriedades novas que não podiam ser antecipadas pelo estudo de seus componentes e dos intercâmbios entre eles.

Certamente, não encontramos situaçôes desse tipo todos os dias em nossa vida - ao menos nas nossas práticas tecnológicas. Para entender como funciona um forno de micro-ondas, basta utilizar as prescriçôes do reducionismo científico. Pois a superveniência (1) de propriedades novas diz respeito a sistemas muito complexos, e de modo geral requer muito tempo e intercâmbios com o meio ambiente, como, por exemplo, a aparição de novas espécies ao longo da evolução. A possibilidade, então, está restrita aos sistemas que chamamos de sistemas termodinâmicos abertos.

Nós, humanos, somos sistemas abertos em constante interação com o mundo. A nossa liberdade, o chamado livre arbítrio, parece ser um exemplo constante de exercício de emergentismo. A criação artística também o é: como a criação poderia livrar-se dos caminhos deterministas do funcionamento do sistema nervoso central se o cérebro não tivesse a possibilidade, pelo menos, de provocar bifurcaçôes entre vários caminhos possíveis das atividades nervosas?

O que significa dizer que a natureza é organizada em níveis, patamares? De que modo esta visão modifica a visão de origem - geralmente associada à visão de uma partícula elementar? A natureza é obviamente organizada em patamares. Conhecemos, por exemplo, o nível dos quarks, das partículas elementares, dos átomos, das moléculas. No campo dos sistemas 
